Provided for non-commercial research and education use. Not for reproduction, distribution or commercial use.

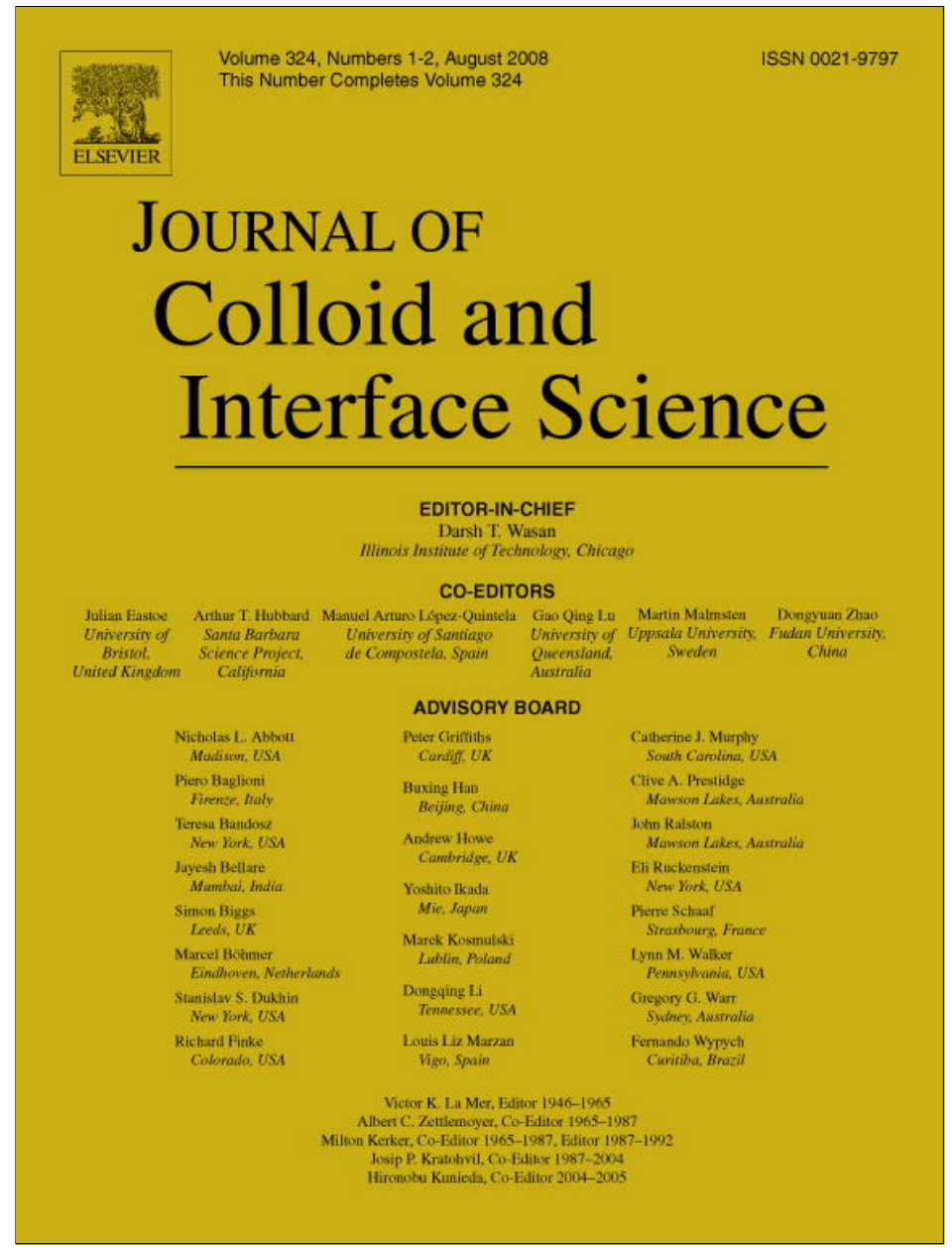

This article appeared in a journal published by Elsevier. The attached copy is furnished to the author for internal non-commercial research and education use, including for instruction at the authors institution and sharing with colleagues.

Other uses, including reproduction and distribution, or selling or licensing copies, or posting to personal, institutional or third party websites are prohibited.

In most cases authors are permitted to post their version of the article (e.g. in Word or Tex form) to their personal website or institutional repository. Authors requiring further information regarding Elsevier's archiving and manuscript policies are encouraged to visit:

http://www.elsevier.com/copyright 


\title{
Self-assembled monolayers of 2-(thienyl)hexylphosphonic acid on native oxide surface of silicon fabricated by air-liquid interface-assisted method
}

\author{
Chih-Wei Hsu ${ }^{a}$, Huei-Ru Liou ${ }^{a}$, Wei-Fang Su ${ }^{a, b, *}$, Leeyih Wang ${ }^{a, c, *}$ \\ a Institute of Polymer Science and Engineering, National Taiwan University, Taipei 10617, Taiwan \\ ${ }^{\mathrm{b}}$ Department of Materials Science and Engineering, National Taiwan University, Taipei 10617, Taiwan \\ c Center for Condensed Matter Sciences, National Taiwan University, Taipei 10617, Taiwan
}

\section{A R T I C L E I N F O}

Article history:

Received 14 February 2008

Accepted 11 April 2008

Available online 29 May 2008

\section{Keywords:}

Phosphonic acid

Silicon oxide

Self-assembled monolayer

\begin{abstract}
A B S T R A C T
A simple, fast, and low-compound-consuming procedure based on the air-liquid interface-assisted method for preparing self-assembled monolayers (SAMs) of organic molecules with phosphonic acid head groups on the native oxide surface of silicon was demonstrated. The SAMs thus prepared were characterized by contact angle measurement, X-ray photoelectron spectroscopy (XPS), Fourier transform infrared spectroscopy (FTIR), and atomic force microscopy (AFM). This approach enabled the fabrication of ordered SAMs in a large-area substrate.
\end{abstract}

(C) 2008 Elsevier Inc. All rights reserved.

\section{Introduction}

Monolayers of amphiphilic organic molecules that form spontaneously on a substrate surface by adsorption from solution are known as self-assembled monolayers (SAMs) and have been extensively studied during the past decade because of their extreme usefulness in surface modification and functionalization. This methodology has numerous potential applications, including adhesion promotion [1,2], microcontact printing [3], chemical/biological sensing [4,5], corrosion resistance [6], and wetting [7]. In the field of SAMs, the Au/thiol system has been investigated extensively because $\mathrm{Au}$ is very stable in an atmosphere that will promote the adsorption of thiols onto the Au surface [8] and the adsorptive ability between the thiol group and gold is very strong and highly stable [9]. In addition to Au/thiol systems, organosilicon compounds have been used for many years to generate SAMs on metal oxide substrates $[10,11]$. Recently, phosphonates or phosphonic acid-bearing molecules have been shown to form ordered SAMs on metal oxide surfaces because the hydroxyl groups on the surface of transition metal oxides, such as titanium oxide, niobium oxide, zirconium oxide, anodized aluminum, and tantalum oxide, are known to interact strongly with phosphonic acids or phosphonates and thus to form relatively stable interfacial bonds [12-14]. However, the literature indicates that phosphonic acid is incapable of forming ordered and compact monolayers on both mica and $\mathrm{SiO}_{2}$ surfaces $[14,15]$. Recently, Schwartz and co-workers developed

\footnotetext{
* Corresponding authors at: Institute of Polymer Science and Engineering, National Taiwan University, Taipei 10617, Taiwan. Fax: +886 223696221.

E-mail addresses: suwf@ntu.edu.tw (W.-F. Su), leewang@ntu.edu.tw (L. Wang).
}

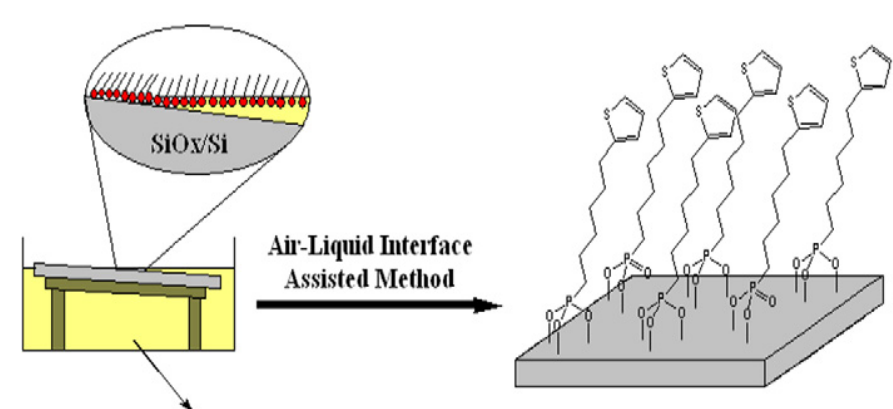

2-(Thienyl)hexyl phosphonic acid Solution

Scheme 1. Schematic illustration of preparing self-assembled monolayers of amphiphilic organic molecules on the native oxide surface of silicon by air-liquid interface-assisted (ALIS) method.

a procedure, called T-BAG (tethering by aggregation and growth), in which the aggregation of organophosphonic acid amphiphiles at the air-solvent interface was transferred to the vertically immersed $\mathrm{SiO}_{2}$ substrate during solution drying, forming compact and ordered monolayers of organic molecules [15]. However, this approach involves a long preparation time. Also, a large change in the solution concentration throughout the preparation process allows micelle formation, which may complicate the aggregation pattern of organic molecules at the air-solvent interface, limiting their ability to form compact SAMs on a large-area substrate.

This work describes a simple procedure for fabricating SAMs of organophosphonic acid amphiphile on the native oxide surface of silicon via an air-liquid interface-assisted (ALIA) method, as in Scheme 1. 


\section{Materials and methods}

\subsection{Synthesis of 6-(2-thienyl)hexylphosphonic acid (THPA)}

To a 250-ml one-necked round-bottom flask that contained 2bromothiophene $(6 \mathrm{~g}, 36.8 \mathrm{mmol})$ was added $50 \mathrm{ml}$ tetrahydrofuran (THF). The solution was chilled to $-78^{\circ} \mathrm{C}$ with liquid $\mathrm{N}_{2}$. Then $1.6 \mathrm{M} n$-BuLi $(27.6 \mathrm{ml}, 44.2 \mathrm{mmol}$ ) was added dropwise via a syringe and stirred for $1 \mathrm{~h}$, followed by the addition of neat 1,6-dibromohexane $(11.3 \mathrm{ml}, 73.6 \mathrm{mmol})$ in one portion. After the solution was stirred for $12 \mathrm{~h}$, the reaction was quenched with water and the resulting mixture was extracted with ether. Removal of solvent with a rotary evaporator afforded a yellow crude product. It was then distilled under vacuum ( 0.5 Torr $)$ at $95^{\circ} \mathrm{C}$ to give 2-(6-bromohexyl) thiophene as a colorless oil ( $4.9 \mathrm{~g}$, yield $=54 \%$ ).

To a suspension of magnesium $(1.55 \mathrm{~g}, 64 \mathrm{mmol})$ in $40 \mathrm{ml}$ anhydrous diethyl ether was added 2-(6-bromohexyl) thiophene (7.97 $\mathrm{g}, 32 \mathrm{mmol}$ ). After being refluxed at $60^{\circ} \mathrm{C}$ for $1 \mathrm{~h}$, the solution was slowly purged into a diethyl ether solution containing diethyl chlorophosphate $(4.7 \mathrm{ml}, 32 \mathrm{mmol})$ and [1,3-bis(diphenylphosphino)-prapane] dichloronickel (II), Ni(dppp) $\mathrm{Cl}_{2}(0.10 \mathrm{~g}$, $0.18 \mathrm{mmol}$ ). The mixture was stirred overnight under reflux and then washed with distilled water. The organic phase was dried over $\mathrm{MgSO}_{4}$ and filtered and the solvent was evaporated. The obtained crude product was purified by silica gel column chromatography using hexane/ethyl acetate $(4: 6)$ as eluent to give 6(2-thienyl)hexyl diethyl phosphonate as a light yellow oil (2.64 g, yield $=27 \%$ ).

To a round-bottom flask that contained 6-(2-thienyl)hexyl diethyl phosphonate $(2.64 \mathrm{~g}, 8.68 \mathrm{mmol})$ and dichloromethane $(25 \mathrm{ml})$ was added bromotrimethylsilane $(2.9 \mathrm{ml}, 21.7 \mathrm{mmol})$. The solution was stirred at room temperature for $8 \mathrm{~h}$. Following the reaction, the mixture was subjected to vacuum distillation to remove by-products. Afterward, the colorless residue was stirred with excess methanol for more than $12 \mathrm{~h}$. The solution was then concentrated directly under vacuum to give a white crystalline product (1.8 g, 85\% yield). ${ }^{1} \mathrm{H}$ NMR (ppm, MeOD): $\delta$ 1.41-1.46 (m, $\left.4 \mathrm{H}, \mathrm{CH}_{2} \mathrm{CH}_{2}\right), 1.62-1.74\left(\mathrm{~m}, 6 \mathrm{H}, \mathrm{P}-\mathrm{CH}_{2} \mathrm{CH}_{2}\right.$ and 2-Th-C- $\left.\mathrm{CH}_{2}\right), 2.87$ (t, 2H, 2-Th-CH ), 6.82 (d, 1H, 3-Th-H), 6.92 (dd, 1H 4-Th-H), 7.17 (d, 1H, 5-Th-H). ${ }^{31} \mathrm{P}$ NMR (MeOD): $\delta$ 30.62. HRMS (ESI) calcd. for 248.06; found 248.0.

\subsection{Preparation of self-assembled monolayers of THPA by ALIA method}

The substrate, which contains a thin oxide layer of silicon, was prepared by subsequently sonicating a single-crystal silicon (100) wafer (area $25 \mathrm{~cm}^{2}$ ) in acetone $(15 \mathrm{~min})$, piranha solution (96\% $\left.\mathrm{H}_{2} \mathrm{SO}_{4}: 35 \% \mathrm{H}_{2} \mathrm{O}_{2}=1: 3,45 \mathrm{~min}\right), \mathrm{NH}_{4} \mathrm{OH}: \mathrm{H}_{2} \mathrm{O}_{2}$ : deionized water $=$ 1:1:5 (30 $\mathrm{min})$, and deionized water (30 $\mathrm{min})$. It was then placed on an adjustable platform, which was horizontally mounted at a tilt angle of $5^{\circ}$ in a glass bath that contained a solution of THPA in ethanol. The highest position of the $\mathrm{SiO}_{x} / \mathrm{Si}$ substrate was set below the surface of the solution by about $2 \mathrm{~mm}$. After evaporation of the solvent had caused the level of the solution to fall below the substrate surface, the substrate was removed and heated in an oven at $140^{\circ} \mathrm{C}$ under $\mathrm{N}_{2}$ for $20 \mathrm{~h}$. The samples were then sonicated in $0.5 \mathrm{M} \mathrm{K}_{2} \mathrm{CO}_{3}$ and subsequently in ethanol/water (2:1) for $30 \mathrm{~min}$ to remove unbound molecules, before being dried in a vacuum oven at room temperature.

\subsection{Characterization}

Surface wettability was investigated by measuring the static contact angles using a First Ten Angstroms (FTA 125) contact angle analyzer at room temperature and ambient humidity with water

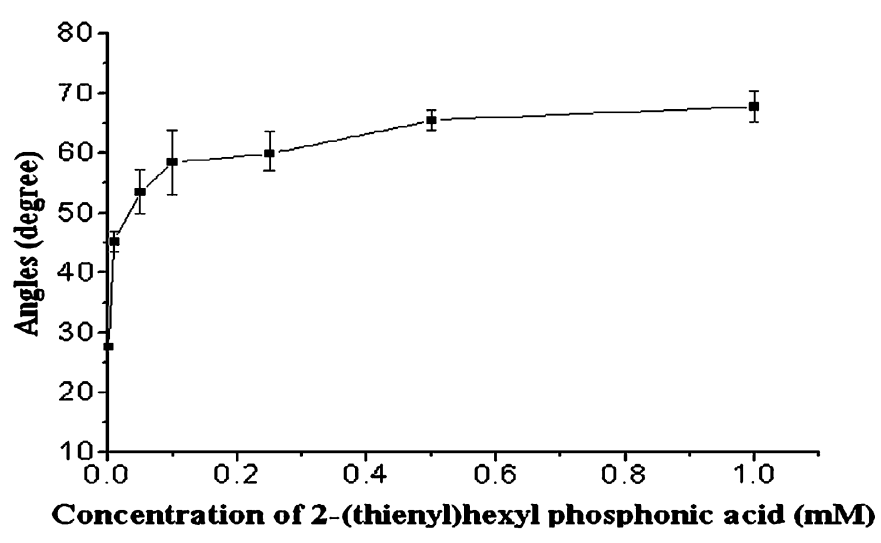

Fig. 1. Static water contact angles of SAMs prepared from different concentrations of 2-(thienyl)hexylphosphonic acid solutions.

as the probe liquid. A 2- $\mu$ l water droplet was placed on the substrate with a syringe. The angle was obtained by estimating the tangent to the drop at its intersection with the surface, and the average of five measurements was taken for reported contact angles. XPS analyses were performed using a VG Scientific ESCALAB 250 system. Spectra were acquired at a base pressure of $10^{-9} \mathrm{mbar}$ using a monochromatic $\mathrm{AlK} \alpha \mathrm{X}$-ray source operated at $200 \mathrm{~W}$. Fourier transform infrared (FTIR) spectra of SAMs were obtained using a JASCO FT/IR 480 Plus spectrophotometer with an attenuated total reflectance (ATR) accessory. Atomic force microscopy was performed in the tapping mode in air using a Digital Instruments Nanoscope IIIa Multimode atomic force microscope. The nominal force constant of the silicon nitride cantilevers (Nanoprobes Ltd.) was $0.12 \mathrm{~N} \mathrm{~m}^{-1}$.

\section{Results and discussion}

Fig. 1 plots the static water contact angles measured on bare $\mathrm{SiO}_{x} / \mathrm{Si}$ and THPA-modified $\mathrm{SiO}_{x} / \mathrm{Si}$ surfaces that were prepared using various THPA concentrations. The results reveal that the water contact angle increased abruptly from $27.6^{\circ}$ for bare $\mathrm{SiO}_{x} / \mathrm{Si}$ to around $60^{\circ}$ as the THPA concentration increased from 0.05 to $0.25 \mathrm{mM}$ and then leveled off at about $65^{\circ}$ at concentrations from 0.5 to $1.0 \mathrm{mM}$, indicating that the formation of a thin layer of THPA on top of $\mathrm{SiO}_{x}$ changed the surface from hydrophilic to hydrophobic.

The XPS scan of THPA-modified $\mathrm{SiO}_{x} / \mathrm{Si}$ in the range $50-800 \mathrm{eV}$ yielded P2s and P2p peaks at around 192 and $134 \mathrm{eV}$, respectively. However, the P2p peak was entirely superimposed by the plasmon loss peak of the silicon wafer. Although the Si-plasmon loss peak at $186 \mathrm{eV}$ interfered with the P2s peak, the two peaks were distinguishable. Accordingly, the P2s peak was selected to analyze THPA SAMs. The XP spectra of THPA-treated $\mathrm{SiO}_{x} / \mathrm{Si}$, displayed in Fig. 2, indicate that the intensity of the $\mathrm{P} 2 \mathrm{~s}$ peak decreased dramatically upon treatment with the $\mathrm{K}_{2} \mathrm{CO}_{3}$ solution and the ethanol $/ \mathrm{H}_{2} \mathrm{O}$ mixture, revealing that the washing step can efficiently remove unbounded THPA. Moreover, the binding energy of P2s shifted from 192.4 to $191.8 \mathrm{eV}$, implying that the phosphonic acid head group was chemically bonded to the $\mathrm{SiO}_{x}$ surface. A similar result has been reported for the SAMs of octadecylphosphonic acid on an oxide-covered silicon coupon [16].

The FTIR spectra of bulk THPA and the THPA-modified $\mathrm{SiO}_{x} / \mathrm{Si}$ substrate are shown in Fig. 3. Upon the adsorption of THPA onto $\mathrm{SiO}_{x}$, the signal in the region $3300-3600 \mathrm{~cm}^{-1}$, corresponding to the $\mathrm{O}-\mathrm{H}$ group in THPA, disappeared, revealing that the adsorbed phosphonate groups were deprotonated. The absorption bands at 1003 and $950 \mathrm{~cm}^{-1}$, corresponding to the asymmetric and symmetric stretching vibrations of the $\mathrm{P}-\mathrm{O}$ group, respectively, were 


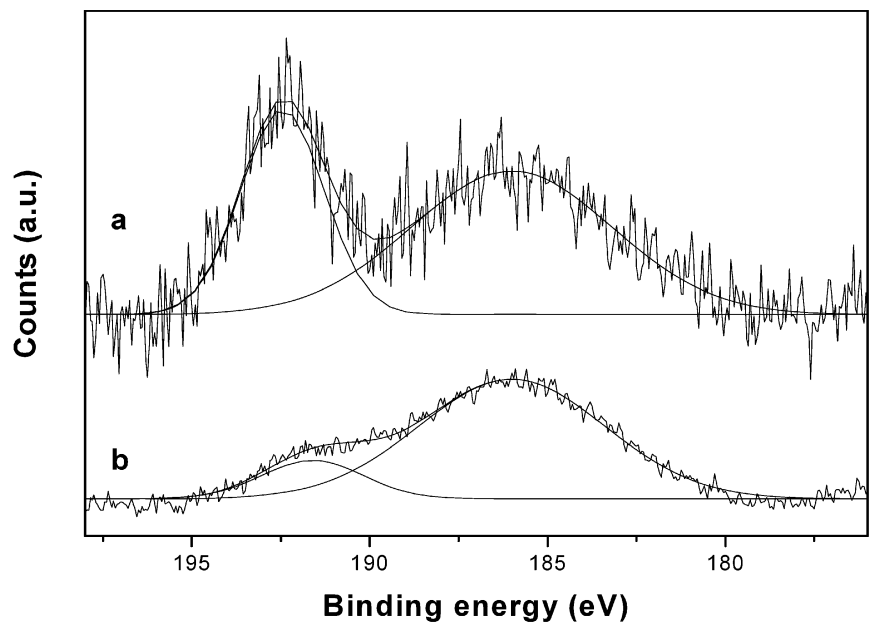

Fig. 2. The P2s signals in the XPS spectra of 2-(thienyl)hexylphosphonic acid SAMs on $\mathrm{SiO}_{x} / \mathrm{Si}$ (a) before and (b) after the washing process.

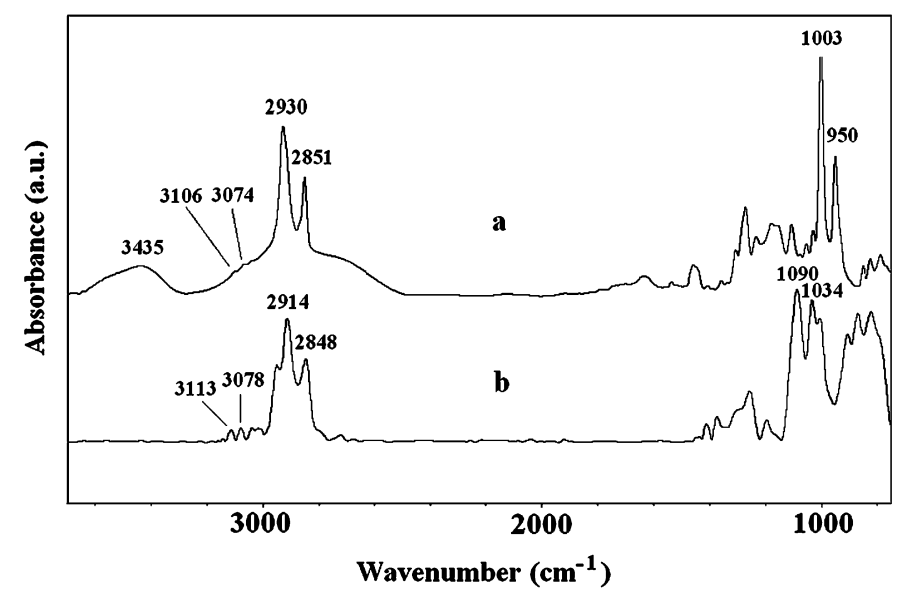

Fig. 3. ATR-FTIR spectra of (a) 2-(thienyl)hexylphosphonic acid and (b) the SAMs of 2-(thienyl)hexylphosphonic acid on $\mathrm{SiO}_{x} / \mathrm{Si}$.
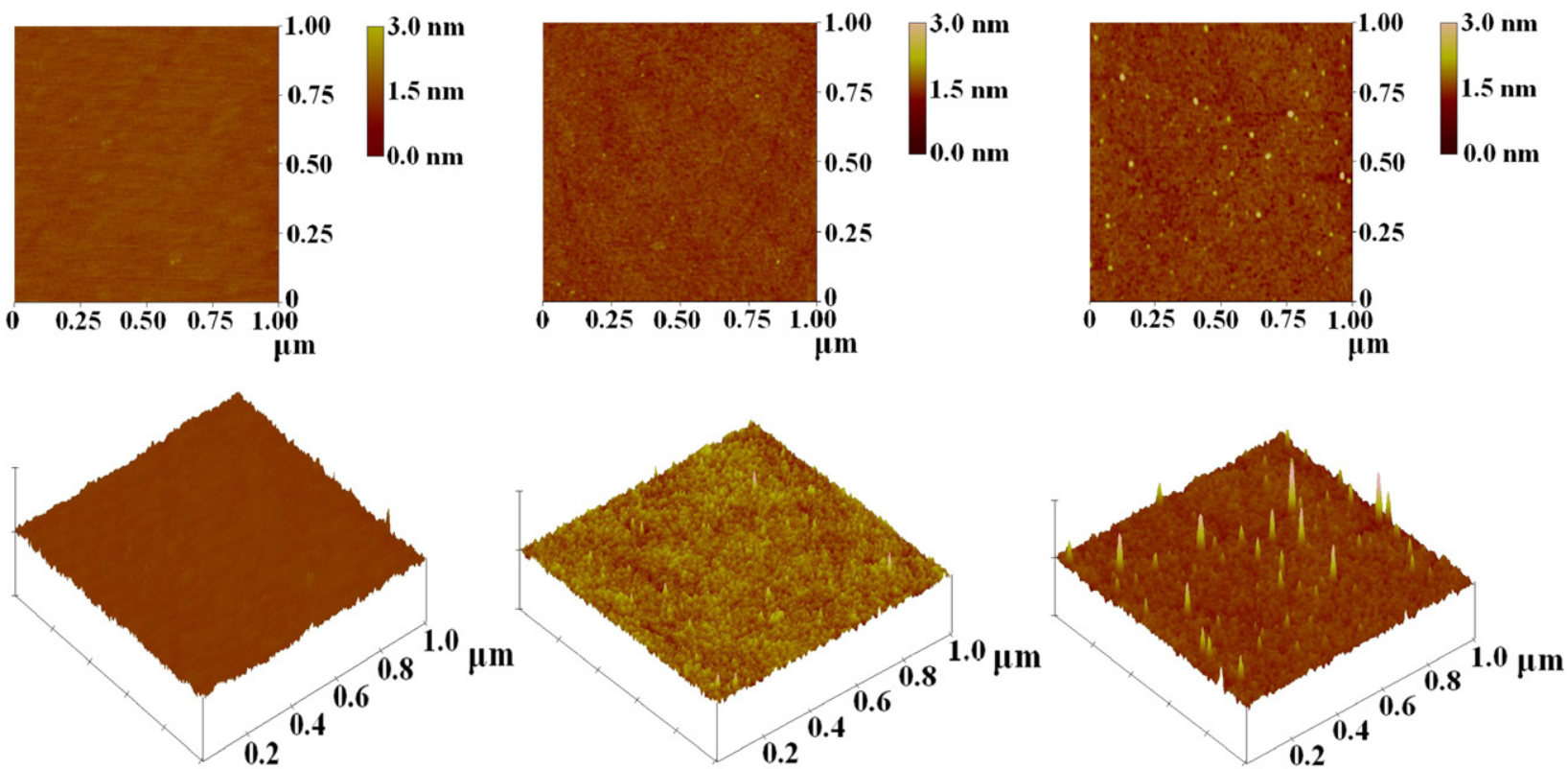

Fig. 4. AFM images (above: height, below: 3D) for pure silicon native oxide (left) and SAMs prepared from $0.5 \mathrm{mM}$ (middle) and $1.0 \mathrm{mM}$ (right) of 2-(thienyl)hexylphosphonic acid solutions. 
cylphosphonic acid, thus reducing the van der Waals force among the alkyl chains.

The surface loading of monolayers that formed on the native oxide surface of silicon was determined gravimetrically using a quartz crystal microbalance (QCM). A quartz wafer with gold electrodes on its surface $\left(196 \mathrm{~mm}^{2}\right)$ was sputter-coated with a thin layer of $\mathrm{SiO}_{x}$ that was grown with self-assembled monolayers of THPA by the ALIA method and then washed with $\mathrm{K}_{2} \mathrm{CO}_{3}$ solution, following the procedure described above. The mass of SAMs was determined from the change of the QCM-measured resonant frequency before and after THPA deposition. It was found to be $47.4 \mathrm{ng}$, which is equivalent to an occupied area per molecule of $17.0 \AA^{2}$. These values indicate that the THPA on $\mathrm{SiO}_{x} / \mathrm{Si}$ prepared by the ALIA method has a packing density similar to that of the octadecylphosphonic acid on $\mathrm{SiO}_{2} / \mathrm{Si}\left(18.5 \AA^{2}\right)$ [15] and 6-(3thienyl)hexanethiol on gold-coated $\operatorname{Si}(111)$ wafers $\left(15.2 \AA^{2}\right)$ [22].

\section{Summary}

Smooth and homogeneous self-assembled monolayers of 2(thienyl)hexylphosphonic acid on the native oxide surface of silicon were prepared by the air-liquid interface-assisted method. The thus-prepared SAMs were packed in an orderly manner with an all-trans configuration, and adhered firmly to the substrate surface. This new method is very simple and fast and requires a small amount of solution, and is therefore suited to large-area SAMs fabrication.

\section{Acknowledgment}

The authors thank National Taiwan University and the National Science Council of Republic of China, Taiwan for financially supporting this research.

\section{References}

[1] E. Jaehne, D. Ferse, H.J.P. Adler, K. Ramya, I.K. Varma, M. Wolter, N. Hebestreit, W. Plieth, Macromol. Symp. 164 (2001) 133.

[2] E. Jaehne, D. Ferse, G. Busch, H.J.P. Adler, A. Singh, I.K. Varma, Des. Monomers Polym. 5 (2002) 427.

[3] M.H. Park, Y.J. Jang, H.M. Sung-Suh, M.M. Sung, Langmuir 20 (2004) 2257.

[4] S.F. Bent, J. Phys. Chem. B 106 (2002) 2830.

[5] H. Liu, S. Liu, L. Echegoyen, Chem. Commun. (1999) 1493.

[6] J.M. Buriak, Chem. Rev. 102 (2002) 1271.

[7] L. Zhang, B. Zou, B. Dong, F. Huo, X. Zhang, L. Chi, L. Jiang, Chem. Commun. (2001) 1906.

[8] G.A. Somorjai, Chemistry in Two Dimensions Surface, Cornell University Press, Ithaca, NY, 1981.

[9] R.G. Nuzzo, F.A. Fusco, D.L. Allara, J. Am. Chem. Soc. 109 (1987) 2358.

[10] Y. Wang, M. Lieberman, Langmuir 19 (2003) 1159.

[11] E. Hoque, J.A. DeRose, R. Houriet, P. Hoffmann, H.J. Mathieu, Chem. Mater. 19 (2007) 798.

[12] E. Hoque, J.A. DeRose, G. Kulik, P. Hoffmann, H.J. Mathieu, B. Bhushan, J. Phys. Chem. B 110 (2006) 10855.

[13] D. Brovelli, G. Hähner, L. Ruiz, R. Hofer, G. Kraus, A. Waldner, J. Schlösser, P. Oroszlan, M. Ehrat, N.D. Spencer, Langmuir 15 (1999) 4324.

[14] R. Hofer, M. Textor, N.D. Spencer, Langmuir 17 (2001) 4014.

[15] E.L. Hanson, J. Schwartz, B. Nickel, N. Koch, M.F. Danisman, J. Am. Chem. Soc. 125 (2003) 16074

[16] I. Gouzman, M. Dubey, M.D. Carolus, J. Schwartz, S.L. Bernasek, Surf. Sci. 600 (2006) 773.

[17] R.D. Ramsier, P.N. Henrisksen, A.N. Gent, Surf. Sci. 203 (1988) 72.

[18] H. Byrd, S. Whipps, J.K. Pike, J. Ma, S.E. Nagler, D.R. Talham, J. Am. Chem. Soc. 116 (1994) 295.

[19] J. Chen, A.R. Murphy, J. Esteve, D.F. Ogletree, M. Salmeron, J.M.J. Fréchet, Langmuir 20 (2004) 7703.

[20] E.S. Gawalt, M.J. Avaltroni, N. Koch, J. Schwartz, Langmuir 17 (2001) 5736.

[21] B.R.A. Neves, M.E. Salmon, P.E. Russell, E.B. Troughton Jr., Langmuir 16 (2000) 2409 .

[22] H. Ahn, M. Kim, D.J. Sandman, J.E. Whitten, Langmuir 19 (2003) 5303. 